\title{
HISTÓRIAS, NATUREZAS E CULTURAS EM AMBIENTES AMAZÔNICOS
}

\section{APRESENTAÇÃO}

Diante da riqueza sociocultural e biodiversidade existente na Amazônia, naturezas, sociedades e culturas se imbricam na e para a composição de modos de vida, ambientes sócio culturais e históricos diversos deste imenso território brasileiro, demarcado por um bioma que o identifica e o diferencia de outros. A presença humana e suas lutas explicitam disputas territoriais milenares com outras mais recentes demarcadas por interesses externos e com fins de apropriação e de dominação de humanos e não humanos, assim como, cada vez mais, tem sido objeto de visitação e revisão dos conhecimentos consolidados de fora para dentro.

Trata-se de uma "Amazônia profunda", pouco conhecida a partir das suas próprias e complexas engrenagens históricas e socioculturais que enxerga a natureza como vida humanizada que se constrói no processo das ações e dos sonhos de (r)existência. De povos e de comunidades, cujas tradições se constroem e se tecem na vida imbricada à mata e ao campo e suas formas diversas de trabalho, de educação e de organização, rural ou urbana. Urge desconstruir e revelar as Amazônias pelas vozes que nela ecoam. Propósito este do presente dossiê da Nova Revista Amazônica, o qual apresenta um conjunto de trabalhos, que buscam compreender as relações construídas entre sujeitos, suas comunidades e os ambientes em que pulsam a vida e suas culturas do contexto amazônico.

Inserido no âmbito das discussões de gênero e protagonismo das "mulheres de letras" no decorrer do século XIX, enquanto exercício do saber-fazer das mulheres paraenses, de Ana Maria Maciel Corrêa, intitulado Escritas e escrituras femininas no século XIX na sociedade paraense da borracha: 1850-1900, discute as escrituras de mulheres publicadas em jornais em Belém do Pará no auge da "Era da Borracha" (18501900). Ao se reportar aos escritos da paraense "Euniciana" em sua "Carta à Enaíra", publicada no periódico "O Beija-flor" (1850) e os excertos trazidos por Germana Salles (2012), sobre a obra "Não é bom brincar com a dor" da escritora francesa Delphine de Girardin, o artigo destaca a mulher intelectual e escritora paraense no transitar do século XIX, como contraponto ao contexto societário local dos anos oitocentista visivelmente caracterizado pelas relações patriarcais, patrimoniais e escravagistas reprodutoras e afirmadoras do poder do homem, elementos limitantes da figura e a escrita literária feminina num cenário de dinamismo cultural da Belle Époque na sociedade amazônica.

Igualmente no campo literário sob o título Imaginação e experiência: natureza e paisagem em fronteiras amazônicas de Márcia Regina Capelari Naxara, apresenta reflexões a respeito de dois livros de Gastão Cruls (1888-1959): o romance "A Amazônia misteriosa" (1925), ficção com reconhecida inspiração em H.G. Wells, e o relato de viagem "A Amazônia que eu vi" (1930), narrativa da Campanha de Inspeção de Fronteiras com a Guiana Holandesa comandada pelo General Rondon. Em suas análises, o artigo destaca como esses textos literários possibilitam acompanhar percursos e itinerários que sustentaram tanto a imaginação histórica e literária, como propiciaram a formulação de alguns dos quadros paisagísticos e mentais elaborados sobre a vasta região amazônica, corroborando para entender como os aspectos relacionados aos espaços,

\footnotetext{
${ }^{1}$ Que não está disponível ao acesso com facilidade ao mesmo tempo em que pouco tem recebido a presença do estado em termos de políticas básicas de proteção ambiental, educação, saúde, entre outras demandas dos povos indígenas, tradicionais e ribeirinhos que ficam isolados muito tempo e solitários nas lutas cotidianas da vida em comunidades.
} 
gentes, paisagens se tornam responsáveis pela construção de aspectos duráveis da memória coletiva que tem se consolidado sobre Amazônia.

Ainda no campo da tematização literária, o artigo As chulas de Ramiro como forma de resistência no romance Marajó, de Dalcídio Jurandir, de Max Silva do Espírito Santo e Gunter Karl Pressler, analisa a expressão e a função da música regional a "Chula Marajoara", no romance "Marajó" (1947), de Dalcídio Jurandir. O romance apresenta a situação do filho e herdeiro único do Coronel Coutinho, Missunga, que não consegue concluir seus estudos e entra em conflito com seu pai por não concordar com as decisões sobre a condução dos negócios da família e a situação dos habitantes no vilarejo e nas beiradas dos rios, no contorno e nas fazendas. Retrata ainda a forma como as chulas do Ramiro surgem e são recebidas pelo povo e, como a música folclórica apresenta o caráter do divertimento e descanso após um dia de trabalho, as chulas compostas pelo protagonista também trazem o caráter político e de resistência, representando homens e mulheres dos trabalhos duros dos campos, lagos e rios do "Marajó", de Dalcídio Jurandir.

O artigo Ethos Amazônida: a poiésis dialógica identitária ribeirinha, elaborado por Larissa da Silva Sicsú, Pedro Rapozo e Eneila Almeida dos Santos se insere no campo das discussões do ser amazônida, o ser situado numa dialogicidade entre sua vivência social e suas inter-relações com o cenário natural do território amazônico, influenciam não somente o seu modo de vida, mas definem, tracejam seus aspectos identitários. Ao questionar a ideia de identidade, perspectiva compreender os processos identitários ribeirinhos, sua poiésis identitária, situando as características identitárias que marcam o ethos ribeirinho, a partir de uma visão multifacetada que possibilita transcrever a poiésis do ser amazônico nas suas práxis diárias, sua autodenominação e protagonismo do sujeito caboclo enquanto ser primordial na sua formação social e de suas vertentes identitárias, superando a ideia do homem amazônida preconcebido ou romantizado.

Com o título Povoado Bica: processos de organização pelo reconhecimento e titulação da terra em Aldeia Velha - Pirapemas (MA), de Tânia Nazarena de Oliveira Miranda, traz como eixo de análise o processo de recomposição territorial erigida pelas comunidades quilombolas do Povoado Aldeia Velha em Pirapemas, no estado do Maranhão. O estudo foi desenvolvido no povoado Bica, por ser um território que expressa o processo político desencadeado pelas lideranças e instituições históricas do Maranhão, que lutam pelo reconhecimento estatal do direito das comunidades afrodescendentes, e descreve como o processo se deu com base nos direitos territoriais, de etnicidade, de organização política e concertações históricas para a conquista de efetivação da titulação da terra, o artigo a destaca as lutas travadas em meio aos conflitos pela terra, a reconstituição da descendência e da tradicionalidade negra centrada na memória social e a etnicidade do grupo, enfatizando o processo de resistência das comunidades quilombolas na Aldeia Velha frente a expropriação territorial, a violência e violação de direitos humanos que ainda ocorrem em pleno século XXI que comprometem a apropriação definitiva do território e as condições da sustentabilidade e a manutenção do modo de vida de seus habitantes.

Desvendar as Amazônias, no entanto, não é um trabalho fácil, implica também em dar visibilidade crítica às vozes que as definiram pelo olhar de viajantes e de naturalistas desde o século XVI. Carla Oliveira Lima, no texto Elos Humanos e Trabalho de Campo na Amazônia de Meados do Século XIX, se propõe a contribuir nesse processo com sua pesquisa acerca das experiências do naturalista inglês Alfred Russel Wallace, em meados do século XIX, em direção ao Rio Negro. A autora nos apresenta possibilidades outras de reconhecer as relações de cooperação e de amizade estabelecidas localmente e extra- 
localmente e que em muito colaboraram para o sucesso ou não das viagens de coleta de espécies e de projeção do naturalista em uma rede de colaboradores profissionais.

No artigo História Ambiental: entre o Passado e o Futuro, Marcelo Lapuente Mahl e Paulo Henrique Martinez historicizam o processo de constituição e de institucionalização dos estudos sobre o meio ambiente, a partir dos anos 70 do século XX, como um campo de ensino e pesquisa, salientando a constituição e a interdisciplinaridade da História Ambiental feita no Brasil.

O interesse em descrever o absenteísmo no processo de produção de dendê, num estudo de caso em uma empresa agrícola do município de Tomé-Açu/PA, leva Rodrigo Fraga Garvão, Warleson Pontes Ribeiro, Robson Cristo Viana e Rayra Brandão a apresentarem, no artigo intitulado Absenteísmo e Produção de Dendê na Amazônia: Trabalho e Qualidade de Vida em Tomé-Açu/PA, as causas e as consequências do absenteísmo dentro da organização. Os dados obtidos por meio de pesquisa documental e bibliográfica, com abordagem quanti e qualitativo, aplicação de questionários, entrevistas e levantamento de índices e de taxas referentes ao absenteísmo nos anos de 2014 a 2018, apontam que a adoção de políticas internas adotadas pela empresa reduz os índices de absenteísmo, mas ainda é emergente a atenção em relação à saúde dos trabalhadores.

Com o intuito de investigar os fatores que influenciaram as possíveis mudanças nas práticas produtivas da mandioca, Josiane Santos da Silva, Lene da Silva Andrade, Andrey Mendonça de Souza, Fabio Halmenschlager, no texto Práticas Produtivas da Farinha de Mandioca na Comunidade Quilombola Mocambo - Ourém - PA, entrevistaram oito agricultores, por meio de um questionário, na comunidade quilombola do Mocambo, em Ourém, Estado do Pará, que tem a agricultura como uma das principais atividades de subsistência física e econômica. Espelho da realidade das comunidades tradicionais próximas aos centros urbanos nos dias atuais, sua população com idade média de 55 anos, de modo geral, estudou até a quarta série; a roça de mandioca varia de 2 a 6 tarefas de tamanho, em muito para a subsistência do próprio grupo. O grupo, no entanto, comercializa quando necessita. As influências externas chegam, todavia, com a pressão do mercado e das novas tecnologias e/ou a ausência dos jovens da comunidade ou do circuito produtivo, que impactam sobremaneira a existência da própria comunidade, que continua a produzir combinando saberes e (novas) tecnologias, mas num tempo e ritmo marcado pela tradicionalidade e pela resistência frente aos desafios impressos pela vida moderna.

Myrian Sá Leitão Barboza, Carla Ramos Munzanzu, Izonara Augusta dos Santos Souza e Edivanei de Oyá trazem, no texto Sem as Plantas a Religião não Existiria: Simbologia e Virtualidade das Plantas nas Práticas de Cura em Comunidades Tradicionais de Terreiros Amazônicos (Santarém, PA), apresentam um estudo preliminar da simbologia das plantas nas comunidades afro-religiosas de Santarém, por meio de levantamento dos diferentes usos e do seu papel das plantas nas comunidades de religiões de matriz africana na cidade de Santarém, bem como o estudo observa as relações que envolvem os sujeitos que mediam e frequentam os citados espaços com fins terapêuticos e observam os cuidados que ultrapassam a visão medicamentosa comumente encontrada nos dias de hoje. Os autores apresentam uma Amazônia urbanizada e tradicional, que se encontra silenciada e marginalizada nas cidades.

Estes autores e autoras com seus textos fazem aqui ecoar as vozes silenciadas e desveladas que dão cores e formas diversas do ser e viver de Amazônias ao mesmo tempo que socializam os conhecimentos produzidos em relações de saberes coletivos da ciência produzida pelos de cá, do lugar. Cada trabalho mostra uma faceta das Amazônias, 
fomentando as reflexões sobre povos tradicionais, culturas e biodiversidade existente no contexto amazônida.

A organização desta edição também busca articular vozes coletivas e em redes acadêmicas que fazem pela pesquisa neste território, suas forças produtivas de ressignificar saberes e práticas decoloniais e pluriversas, como são os povos, as naturezas e suas potencialidades de ser vida, para apresentar esta edição da Nova Revista Amazônica, no período das águas. Esperamos que se alargue os conhecimentos sobre o tema e que as discussões no dossiê apresentadas inspirem novas pesquisas

\section{As organizadoras}

\section{Francilene de Aguiar Parente}

Doutora em Antropologia, Professora Adjunto da Universidade Federal do Pará (UFPA), do Programa de Pós-graduação em Educação e Cultura (UFPA) e do Programa de Pósgraduação em Educação Escolar Indígena (UEPA/UFPA/UFOPA/UNIFESSPA). ViceLíder do Grupo de Estudos Afro-Brasileiro e Indígenas (GEABI). E-mail: faparente@ufpa.br

\section{Irlanda do Socorro de Oliveira Miléo}

Doutora em Educação: Currículo pela Pontifícia Universidade Católica - São Paulo. Professora Adjunta da Universidade Federal do Pará/Campus Universitário de Altamira e do Programa de Pós-Graduação em Currículo e Gestão da Escola Básica PPEB/UFPA). Líder do Grupo de Estudo e Pesquisa em Educação, Currículo e Cultura (GEPECC). Email: irlanda@ufpa.br

\section{Beleni Saléte Grando}

Pós-doutora em Antropologia Social, Professora do Programa de Pós-Graduação em Educação da UFMT; Coordenadora do Projeto "Ação Saberes Indígenas na Escola" em Mato Grosso e do Procad-Amazônia Rede UFPA-UFMT-UFAM. Líder do Grupo de Pesquisa Corpo, Educação e Cultura (COEDUC). E-mail: beleni.grando@gmail.com

\section{Hellen Cristina Picanço Simas}

Professora Associada da Universidade Federal do Amazonas e da Coordenação de Aperfeiçoamento de Pessoal de Nível Superior. Possui doutorado e mestrado em Linguística pela Universidade Federal da Paraíba; Pós-doutorado em Estudos da Linguagem pela Pós-graduação em Estudos da Linguagem da Universidade Federal Fluminense - UFF; graduação em Letras Língua Portuguesa pela Universidade Federal do Amazonas. Membro do programa de Pós-graduação em Educação (PPGE), da Universidade Federal do Amazonas. Membro da Comissão de Línguas Ameaçadas da Associação Brasileira de Linguística - ABRALIN. Líder do Núcleo de Estudos de Linguagens da Amazônia (Nel-Amazônia/CNPq). E-mail: hellenpicanço@ufam.edu.br 